\title{
Spontaneous Centric Fusion Leading to $2 n=39$ Chromosomes in the Laboratory Mouse
}

The Swiss albino mouse, Mus musculus, possesses at the mitotic metaphases characteristically 40 telocentric chromosomes. ${ }^{1}$. A very minute second arm may be observed erratically in some of the chromosomes ${ }^{2}$. The only deviation from the characteristic number to $2 n=39$ telocentrics, was reported in a $\mathrm{C}_{3} \mathrm{H}$ mouse with primary adenocarcinoma ${ }^{3}$, while the present communication accounts for phenotypically 2 normal males and 2 females but heterozygous for a centric fusion of two telocentrics leading to $2 n=39$ chromosomes (Figures 1 and 2) obtained from 2,000 mice examined by us since 1968. These heterozygotes were discovered in an inbred stock from a local dealer from whom we have been receiving a regular supply of mice for our various experimental studies $^{4-6}$. After the discovery of the first heterozygote ${ }^{7}$, we waited for critical confirmation, because that individual was treated with a phenolic compound for other purposes and it contained a limited number of clear metaphases. In the subsequent years, 2 female and 1 male heterozygotes under report were discovered but they were also among samples which were treated with penicillin, barbital and Staphylococcus aureus respectively. Incidentally, none of the 300 control specimens were found to be heterozygous for the centric fusion. Nearly 100 metaphases of the bone marrow cells from each of the 3 heterozygotes were examined and they invariably contained 38 original telocentrics and 1 metacentric, the latter being formed by the centric fusion of two telocentrics belonging to groups II and III (Figures 1-6), if the chromosomes were karyotypically arranged into 5 groups according to CRIPPA ${ }^{1}$. A comparison of the metaphase complements of all the heterozygotes indicated that the metacentric was present in all of them. It showed some variation in length in different plates of the same individual (Figures 3 and 4 of a female and Figures 5 and 6 of a male) depending upon the stage of division and the effect of the colchicine-citrate-air drying technique employed for the bone marrow chromosome preparations. The metacentric chromosome fluctuates in the frequency of $0.2 \%$ for the colony from which specimens are being regularly supplied for our work. Some individual homozygous for 2 metacentrics with $2 n=38$ chromosomes is expected in a frequency of $0.04 \%$ if the said condition is not lethal, but our data are still below the mark.

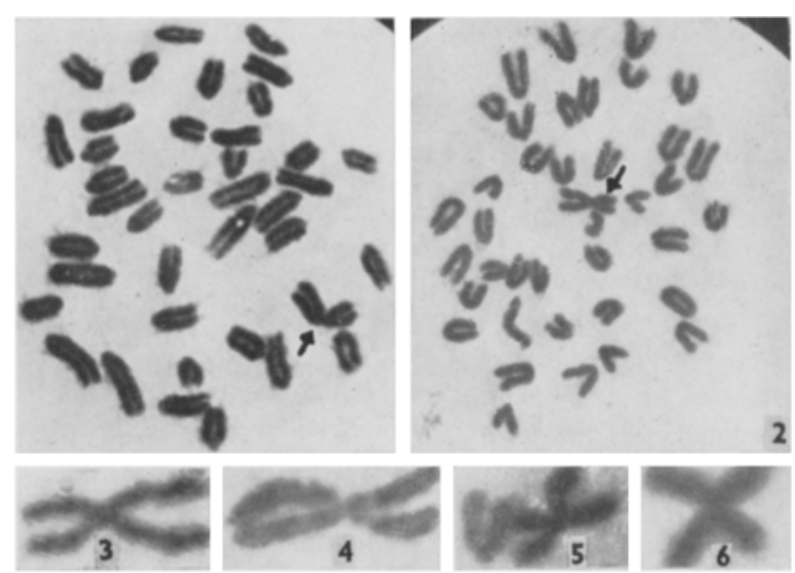

Figs. 1-6. Photomicrographs of the metacentric chromosome in the metaphase complement of a male (Figure 1), and a female (Figure 2) and shown individually of a female (Figures 3 and 4) and of a male heterozygote (Figures 5 and 6 ).
Besides the four heterozygotes referred to above, an examination of generally 100 metaphases per individual of 1,200 mice treated with various physical, chemical and living mutagens ${ }^{4-6}$ revealed very rarely 1 or 2 complements containing a biarmed chromosome of metacentric or submetacentric type, in which case the centric fusion definitely resulted due to the treatment with some kind of mutagen. It could never be the constitutional one because its frequency was negligible in comparison to cent percent metaphases containing the very particular metacentric chromosome in the fusion heterozygotes. On the other hand, it is absurd to think that the very metacentric found in all the metaphases of the heterozygotes had its independent origin due to the treatment with 4 different mutagens mentioned above; and secondly it spread in all the cells within $48 \mathrm{~h}$ after the treatment. Therefore, it can firmly be concluded that the very metacentric had its origin in the past and the heterozygotes inherited it on fertilization at the beginning of their life. It had no connection with the treatment by the mutagens.

In the origin of a metacentric by the centric fusion of two acrocentrics, a supernumerary chromosome is also expected according to the hypothesis of WHITE ${ }^{8}$. But it coult not be substantiated here as none of 2,000 individuals was found with a supernumerary in the colony concerned. It may be argued that the supernumerary was lost soon after the origin of the metacentric. Alternatively it is suggested that the metacentric could have originated by the fusion of the eroded centric ends of the two telocentrics leaving no supernumerary element. In that case the chromosome concerned is a dicentric one possessing two centromeres in very close proximity behaving as one. The extended centromeric region of the metacentric in some plates (Figures 2 and 4 ) may support the suggestion of the dicentric nature of the metacentrics in LP 59 cell line ${ }^{9}$. Anyhow the heterozygotes maintained the Robertsonian principle in having 40 'fundamental arms' 10 .

Zusammentassung. Es wurden unter 2000 Einzeltieren einer Kolonie von Schweizer Albinomäusen 4 Heterozygoten mit metazentrischem Chromosom erhalten. (Zentrische Fusion zweier Tolozentren der Gruppen II und III : $2 n=39 ; 8 \%$ Tolozentren und ein Megazentrum.)

G. K. Manna, S. Bardhan, S. Chakrabarti, S. Gupta and A. B. Mitra

Department of Zoology, University of Kalyani, Kalyani (West Bengal, India), 20 February 1974.

1 M. CRIPPA, Chromosoma 15, 301 (1964).

${ }^{2}$ M. L. BECAK and W. BECAK, Experientia 29, 359 (1973).

${ }^{3} \mathrm{~J}$. H. TJro and G. Ostergren, Hereditas 44, 451 (1958).

${ }^{4}$ G. K. Manna, Proc. 56th Indian Sci. Congr., Pt. 2, Presidential Addresses (1959), p. 185.

5 G. K. Manna, Proc. 1st All India Congr. Cytol. and Genet., J. Cytol. and Genet., Congr. Suppl. (1971), in press.

${ }^{6}$ G. K. Manna, Proc. 43rd Ann. Meet. of Nat. Acad. Sci. India, Presidential Address, Sec, of Biological Sciences, 1 (1973).

7 A. B. Mitra, Mammal. Chromos. Newslett. 12, 93 (1971).

8 M. J. D. White, Animal Cytology and Evolution 3rd edn. (Cambridge University Press, Cambridge 1973), p. 218.

${ }^{9}$ G. K. Manna, Cytologia 27, 43 (1962).

10 R. Matthey, Experientia 1, 58 and 78 (1945). 